\title{
Culturally-Responsive Mathematics Pedagogy Through Complexivist Thinking
}

\author{
WENDY S. NIELSEN, CYNTHIA NICOL AND JENIPHER OWUOR \\ University of British Columbia (Canada)
}

\begin{abstract}
This paper uses a complexity lens to consider the pedagogical project of culturally responsive mathematics. Need for new and different theoretical perspectives for Aboriginal education arise from chronic underachievement among Canada's Aboriginal students. Culturally responsive mathematics pedagogy as a complex learning system allows a different view into the interrelationships and necessary conditions between culture, education and society, a view that aims to open new possibility for curriculum development, Aboriginal schooling and cultural renewal, while ensuring success for students.

As part of the \$11 million school project, the Band School Society negotiated with the Federal Aboriginal Affairs Ministry and the building contractors to include apprenticeships for Band members to join the work crew hired to build the new school. For an Aboriginal village of 2000 people and up to 80\% unemployment, this was a great opportunity. Interested workers were invited to apply for the positions. All 15 of the respondents were hired immediately, and all needed mathematics upgrading courses to enter the apprenticeship training program. Skilled trades workers were in short supply in the community, and so future employment opportunities were virtually assured after completion of the school project. A local, non-Native adult education teacher was enlisted to run an evening prep course for these newly hired apprentices. The course offered focused training in mathematics skills needed by tradespeople, and indeed, these were prerequisite skills for entering the apprenticeship program. On the first night of class, eleven men and women arrived. By week two, the group had dwindled to six. When the course was completed at the end of eight weeks, two students earned completion certificates and formally entered the apprenticeship program.
\end{abstract}

Complicity: An International Journal of Complexity and Education

Volume 5 (2008), Number $1 \bullet$ pp. 33-47 •www.complexityandeducation.ca 


\section{Introduction}

Aboriginal ${ }^{1}$ students around the world experience conventional schooling with a demonstrated lack of enthusiasm (Battiste, 2002; Cooper, Baturo, Warren, \& Doig, 2006; Ezeife, 2002). This holds true for mathematics courses at the high school level, as only about $8 \%$ of Aboriginal students participate in Principles of Mathematics 12, compared to $34 \%$ of non-Aboriginal students (British Columbia Ministry of Education, 2006a, 2006c). A significant consequence is that few Aboriginal students take higher-level courses in mathematics, attend post-secondary programs that require mathematics and are generally underrepresented in careers that use mathematics. It is thus reasonable to argue for the need to challenge 'conventional' approaches to instruction and indeed, schooling, and consider alternatives, particularly for Aboriginal learners. Culturallyresponsive approaches to classroom pedagogy have shown promise among both Aboriginal and non-Aboriginal learners in Alaska (Lipka, 2002; Lipka, Webster, Yanez \& Andrew-Ihrke, 2006).

This paper adopts a complexivist view toward culturally-responsive approaches to mathematics teaching in order to enhance our understanding and operationalization of the multi-faceted domain of Aboriginal education through culturally responsive pedagogy. The paper discusses current perspectives on culturally-responsive mathematics pedagogy and develops how complexity thinking can elaborate these understandings. The nature of this work offers fruitful and generative possibilities for student engagement with mathematics as well as potential for development of deeper connections and understanding of the self as a member of a community, cultural group and wider society. For teachers, in working to develop culturally-responsive approaches to teaching within a cultural setting that is likely to be different from their own, the approaches offer an opportunity for rich and meaningful professional development.

\section{Culturally-Responsive Approaches to Mathematics Education}

The need to develop non-traditional approaches to teaching in science and mathematics arises out of perennial low success and low participation among Aboriginal students in North America (Barnhardt \& Kawagley, 1998, 2005; Cajete, 1994). The province of British Columbia [BC], which is in the southwestern region of Canada, introduced three choices for Grade 10 mathematics in 1996. Mandatory provincial assessments for Grade 10 mathematics were introduced in 2005 and passing one of the Grade 11 courses is a minimum requirement for graduation. The Grade 12 courses are optional (for

\footnotetext{
${ }^{1}$ In this paper, literature is cited from research in Canada, the United States, New Zealand and Australia. In the various research contexts, different terminology is used for groups of people who inhabited the land before the arrival of Europeans. We acknowledge that terms such as Aboriginal, First Nations, tribes, Native and Indigenous, among others, have particular historical and contemporary significance in their usage. When citing this research, we will observe the convention of referring to the term used in that particular research context by the author cited. The term Elder is capitalized throughout out of respect for those who have community knowledge and wisdom that are shared through education.
} 
graduation) and have involved Provincial Examinations for many years, and have recently been made optional (BC Ministry of Education, 2007). Students choose one of three pathways upon entering Grade 10: "Principles" is the university-track course, and highly theoretical; "Applications" is the more technical and less theoretical course; and "Essentials" is the minimum for graduation credit. Assessment data for these Grade 10 courses indicate that only $29 \%$ of Aboriginal students participate in Principles of Mathematics 10 [PM 10], while 7\% participate in Applications of Mathematics 10 [AM 10] (BC Ministry of Education, 2006a, 2006c). Students are generally expected to continue in the chosen track, as long as they are successful, although opting into "Essentials" is possible from either of the other pathways (but the converse is not possible). Grade 10 Principles or Applications courses are generally considered to be required for further study in sciences or mathematics or admission to apprenticeship programs. This compares to an average participation rate of $65 \%$ of non-Aboriginal students for PM 10. According to the Industry Training Authority (2007), Principles of Mathematics 12 [PM 12] is recommended or required for post-secondary programs. PM 12 is generally taught as a university-entrance course, at a highly theoretical level, surveying major topics in mathematics including exponential functions and logarithms, conic sections, translations and transformations and combinatorics (BC Ministry of Education, 2000). Aboriginal students' participation in PM 12 has hovered around 8\% for nearly 15 years (BC Ministry of Education, 2004, 2006c), representing a significant leak in the mathematics pipeline between Grades 10 and 12, as well as under-representation by Aboriginal learners at all levels of Principles of Mathematics. Among non-Aboriginal students, 35\% take PM 12 (BC Ministry of Education, 2006b, 2006c). While it could be argued that not enough students (Aboriginal or non-Aboriginal) take Principles of Mathematics 12, the fact that fewer Aboriginal students enroll in senior mathematics courses dictates a significant limit to their potential participation in advanced studies of mathematics or careers that require mathematics.

These trends are noted in other regions of Canada (Coalition for the Advancement of Aboriginal Studies [CAAS], 2002) and have had devastating effects, both for students on an individual level, but also for communities that rightfully expect the educational system to prepare young people to enter the adult world of citizenship and participation in the work of society. This is particularly so for Aboriginal communities seeking to develop infrastructures that depend less on outside community experts and more on local experts, personnel and resources (Ezeife, 2002). Yet, as a result of their educational school experiences Aboriginal students learn self-doubt that is so entrenched that they discount their inherent experiences, capacities, and gifts (Battiste, 2002).

In order to address these issues, educators emphasize the need for strong mathematics and science programs in schools in Aboriginal communities, and the use of pedagogical approaches that are based in local culture. D'Ambrosio (1990) argues that ethnomathematics [EM], lying at the intersection of cultural anthropology and history of mathematics, offers a reconceptualization of mathematics education that combats "the negative self-esteem [that] is particularly strong among minority students of mathematics" (p. 22). Ethnomathematics recognizes that cultural productions have 
mathematical elements. Teaching through cultural productions thus has the potential to connect students to their own cultural heritage alongside a conception of mathematics as a component of a democratic and just society.

Bishop (1994) and others (e.g. Lipka, 2002) extend this view of EM to also include historical approaches that look at mathematics in non-western societies, using a sociocultural approach that examines specific mathematical knowledge and practices of different cultural groups within a given society. Other pedagogical approaches have been developed through a Frierian liberatory framework, with particular concern for social justice and equity (see for example, Aylward, 2007; Gutstein, 2006; LadsonBillings, 1995). These culturally-relevant approaches seek to challenge the hegemonic discourses of traditional western knowledge structures and empower all students through the development of mathematical understanding. Lipka (2002) has reflected on the benefit of explicit teaching of Native culture and language for Aboriginal students. Lipka's group has developed curriculum through mathematics concepts embedded within local cultural activities. This work has been called culturally-responsive and has served to re-imagine the work of teachers in Native communities.

\section{Culturally-Responsive Pedagogy}

Culturally-responsive teaching approaches are rooted in students' and communities' cultural knowledge. For many Aboriginal communities this entails re-visioning educational systems to balance the goals of revitalization of cultural and linguistic identities with promoting greater participation by Aboriginal people in the wider society (Battiste, 2002; Battiste \& Barman, 1995; CAAS, 2002; Royal Commission on Aboriginal Peoples [RCAP], 1996). Culturally-responsive teaching seeks to enhance students' academic involvement in the learning process while honoring the importance of Aboriginal perspectives and worldviews. It is an approach to teaching that focuses on Aboriginal students' identities and self-esteem, as well as the cultural integrity of the community. Culturally-responsive pedagogy also intends to address Bishop's (1988) critique that mathematics and mathematics teaching are hegemonic discourses that distance and exclude students from non-western backgrounds or heritage.

Goals of culturally-responsive pedagogy include those offered by Aboriginal scholars and researchers on Aboriginal education in Canada (Battiste, 2002, 2004; CAAS, 2002; Hampton, 1995; Leavitt, 1995; RCAP, 1996) as key for consideration in transforming Aboriginal education. These include: decolonizing classroom environments; incorporating Aboriginal knowledge and worldviews into the curriculum; adopting inclusive pedagogies; and, developing strong community participation in education. Decolonizing classroom environments means that so-called western knowledge takes a more appropriate place as one possible knowledge system in the world. This is not to devalue western mathematics. Rather, the goal is to help build bridges for students to engage meaningfully in the experience of schooling and then function in a wider society that requires mathematics knowledge (Ezeife, 2002). Decolonizing mathematics classrooms requires respectful inclusion of Aboriginal cultures, knowledges and languages in the curriculum alongside appropriate 
pedagogical approaches. Curricula and pedagogy need to be respectful of and responsive to students' traditional cultures and ways of coming to know about the culture, its knowledge structures and its practices. This will involve a deliberate process of integrating Aboriginal knowledge into the school curriculum, and in some cases, first reclaiming Aboriginal knowledge and language. A means toward reclaiming these knowledges, languages and cultural traditions has been an explicit goal for local schools in Aboriginal communities.

For teachers, culturally-responsive pedagogy can present challenges. To attend to the socio-emotional and cognitive needs of all students, particularly to those students whose cultural backgrounds differ from the teacher's, requires a cultural border crossing (Aikenhead, 1996; Nielsen \& Nashon, 2007). To cross the border between their own, often taken-for-granted, assumptions about students' social, emotional and cognitive needs, teachers need opportunities to build understandings of local cultural practices and values, which in many cases are different from their own. Thus culturallyresponsive teaching involves teachers in examining their own tacit assumptions and actions about the motivations and behavior of students, parents, and pedagogies, as well as the uniformity and neutrality of knowledge production. It further involves consideration of institutional and systemic issues that promote inequalities. However, as Battiste (2002), Leavitt (1995) and others note, non-Aboriginal teachers might be limited in their understanding of Aboriginal cultures, particularly with regard to choice of teaching strategies. This could also be true for Aboriginal educators who may not have had access to cultural knowledge and ways of knowing due to colonization. Indeed, Yamauchi, Ceppi and Lau-Smith (2000) report that Native Hawaiian teachers experienced a transformative process around their own cultural attitudes in order to integrate Hawaiian culture and language into the school curriculum. This means that strong connections between individuals in the community and the intentions and efforts of the school are vital.

Lipka et al.'s (2006) mathematics curriculum projects have demonstrated the viability and success of a culturally-responsive approach both for Aboriginal students on reserve and non-Aboriginal students in urban settings. These curricula are developed in collaboration with community Elders, practicing teachers, and researchers through networking and dialogue opportunities between teachers, community members, and teacher education institutions (Battiste, 2002; CAAS, 2002; RCAP, 1996). Networking and dialogue can provide teachers with opportunities to develop communities of learners with their students, teachers from the Aboriginal community, parents, and Elders. This could lead to personal transformation from roles as teachers to students (CAAS, 2002; Freire, 1994), from not knowing to knowing about Aboriginal cultures and worldviews. It requires a responsive relationship within and between teachers, students, parents, Elders, and community members. These are relationships that exist within and across formations of individual classrooms, schools and society in general. Honoring all of these important aspects of worldviews and personal lives requires a wide-reaching perspective that is open to emergence. It is important to engage the hearts and minds of Aboriginal learners (Battiste, 2002), and focus on changes that will lead to diminishing 
the current disparity between Aboriginal and non-Aboriginal participation rates in high school mathematics. Rather, we need a way to consider the nested set of relationships among and between the lived experience of Aboriginal learners, their cultural and social connections and the experience of mathematics in the classroom. Complexity thinking offers such a view.

The well-worn building under replacement and surrounding teacherages had been enclosed by an 8-foot chain link fence when many of the apprentices and their parents were students. The physical separation of the school compound (and its non-Aboriginal inhabitants) from the rest of the village was a very recent memory. As young people, now adults, working to become skilled tradespeople was a significant source of community and personal pride.

\section{Complexivist Thinking}

Complexity science attempts to explore how components or agents within a system selforganize and evolve into complex, purposive and coherent unities. Complex systems as learning systems are "adaptive, self-organizing phenomena" (Davis, Phelps \& Wells, 2004), and like other kinds of complex systems, are nested within multiple layers and realities, each with a series of interconnections and interrelationships that define and constrain them. The interactions between agents in the system are the basis for building meaning (Capra, 2002; Cilliers, 1998; Maturana \& Varela, 1987). Agents must therefore be enabled to interact in multiple, meaningful ways. Interactions among agents happen between and across these layers, but also across adjacent and overlapping systems. Thus, depending on the system, layers of particularity are transphenomenal and transdisciplinary (Davis, 2004, 2007).

Aspects of educational systems have been described as complex entities (Davis \& Simmt, 2003; Davis \& Sumara, 2001, 2006). But, it is not enough to merely label and describe entities as complex. The real power of such work lies in utilizing the built-in relations and interactions as generative, creative and enabling forces for developing stronger, more meaningful pedagogical approaches for classroom work. With a view toward culturally-responsive mathematics pedagogy as a complex learning system, this paper builds on research literature from complexity thinking in education.

The learning system, be it a building project, Band School Society, or pedagogical project, operates at the level of the community, school, classroom, teacher, student or worker, and responds to the environment situationally through a structural coupling between itself and the surroundings. As it responds, it learns and develops (Capra, 2002). The surrounding environment also constrains activity, but not in a deterministic way. Rather, environment and activity co-specify one another. Pedagogical projects as bounded systems are constrained and structured by a variety of influences, from the physical space of the classroom, its populations and personalities to the culture of the school and local community to teachers' background knowledge and beliefs about their own self efficacy. Sufficient openness must be allowed for individual interests and experiences to contribute to the collective effort, but constraints enable collective and collaborative behavior that helps build meaning for both the individuals and the 
collective. Specific attention to local culture in teaching practice includes the possibility for an appropriate level of openness that is coupled to the needs of the local community.

The classroom thus becomes a collective that must have some organizational structure, but not too much (Capra, 1996). In a classroom, structures that control activity can be found at different levels of analysis: the teacher who designs and leads individual activity or seatwork, or group interactions on a large-scale inquiry-based project (Davis \& Sumara, 2001). Our construction apprentices are simultaneously Band members, students in an apprenticeship program (that has its own set of structures and constraints), and workers on a multi-million dollar project. These are interrelated, nested layers in which agents coexist and co-implicate each other and the system. The apprenticeship system structures relations, but so do the other layers.

The networked system that is culturally-responsive pedagogy involves teachers, students, parents, community members and Elders as well as university researchers. Each operates under different (and sometimes competing) agendas, such as the need to maintain and share cultural knowledge, the delivery of prescribed Provincial curricula or a focus on researching the entire process of the developing system. Each of these various aspects are enabled and constrained on different levels.

Social systems are likewise bounded, non-linear and asymmetrical (Cilliers, 1998). Relations of power within the system give rise to competition that reinforces asymmetry. Asymmetries are readily visible in a system that is developing culturally-responsive pedagogy: relations between Eurocentric modern/post-modern and Indigenous postcolonial perceptions (Battiste, 2005); relations between holders of cultural knowledge and those who want to call upon this knowledge; those who conceive the project and its changes as beneficial and those whose own position in a social hierarchy depends on the status quo; students who feel disaffected by their experience of culturally-unresponsive pedagogy and the potential of more appropriate pedagogies.

The school building project turned out to be overly ambitious on many levels. The new buildings were unconventional in their shapes, with the need for complicated carpentry for the unusual angles in corners, stairways and roof lines. These are not the sorts of jobs generally given to first or second year apprentices, and the mathematics needed for such carpentry was weak at best among the locally-hired workers. In fact, significant project delays, wasted materials and cost overruns were directly attributed to weak mathematical knowledge, whereby sub-foremen and crews misread plans and miscalculated cuts, resulting in costly overtime or job site shutdowns while journeymen dismantled the faulty construction and rebuilt as necessary, this time according to specification, and often, after regular working hours.

It is clear that public school education had not provided an adequate mathematical foundation for the apprentices on the school building project. We cannot know how this might have been different had these adults encountered a more culturally-responsive school system when they were younger. What we do know is that the traditional, western-based knowledge system with its associated beliefs and pedagogies failed these students. Culturally-responsive approaches open up new possibilities for re-imagining the project of mathematics education and education more generally for all students. 
It is important to remember that classrooms are also social systems that are selforganizing and dynamic, much as living systems, social networks and communities are. Such systems do not behave mechanistically, contrary to how they are often viewed by teachers, educational administrators and even members of society. While teachers organize for instruction and manage activity in the classroom, it is often the case that outcomes do not reflect intentions at the level of input (Davis \& Sumara, 2001). In a sense, classrooms do not lend themselves to being controlled mechanistically, hence, the appropriateness of viewing the system of schooling as a complex system. The system's perpetual novelty (Waldrop, 1992) makes it difficult to view teachers (or curriculum) as central controllers for activity within a classroom. Much of this has to do with the diversity of elements that make up the complex system.

The individual agents within the system are unique, having different characteristics and potential contributions. For people working within a complex system, this also includes experience levels, educational backgrounds, subject expertise and expectations, cultural background and social awareness. The varied perspectives are where the system itself has its own intelligence, since difference creates space for the generation of new ideas and the possibility represented by individual capability expands. The whole is greater than the sum of its parts (Simon, 2005). This may seem an obvious consequence of people working together, but in traditional models of schooling and approaches to curriculum, assumptions are made about all individuals beginning at the same point (age 5 or so) and arriving at the same end point of the educative process (e.g. Provincial Examinations and Graduation around the age of 18 at the end of Grade 12). In other words, diversity is not something that is traditionally honored in school systems or classrooms.

The project of culturally-responsive pedagogy depends upon a diversity of people with varied knowledges and contributions to make to the project. At the core of the project is traditional knowledge held by Elders and members of the Aboriginal community. A pedagogy that invites this knowledge (and its holders) into planning for curriculum and instruction represents a space to consider how this internal diversity becomes a meaningful component of the system. The goal is to encourage interconnections, which evolve as the complex entity does. Also, interactions among the agents within the system must be enabled, not necessarily so that every part is connected to every other part, but that significant contact enables "notions to bump against one another" (Davis \& Sumara, 2006, p. 143). This is where the richness and diversity of the collective becomes expansive. Cilliers (1998) refers to these interactions as being shortrange in terms of their influence. However, the influence can be immediate and significant as events and their impacts reverberate through the system.

In a culturally-responsive approach to mathematics pedagogy, the initial work is to bring these neighbors into proximity and facilitate interactions, such that this common language and experiential base can develop. These neighbor interactions inform our understanding of the important relations between teachers and students, students and the curriculum, teachers and their colleagues, as well as teachers and parents (Burris, 2005). For our construction apprentices, the interactions also included a new body of 
content information and new processes to be learned. Interaction occurred on many levels: the preparatory mathematics course and its instructor; their fellow apprentices and other workers brought in as subcontractors on the school project; a somewhat linear system of construction management that included a hierarchy of skilled tradesmen and supervisors; plus the contracting company and the many other sub-trades present on the job site. Part of the transformative potential of culturally-responsive approaches to mathematics pedagogy arise out of neighbor interactions as seeds for possibility. When groups of people, such as apprentices on a jobsite, students in a classroom, and/or teachers engaged in a professional development activity or curriculum development project begin their work together, an initial exploration of the entry-level common ground ensues. But this interaction is neither easy nor guaranteed to have a particular desired result. Through time and dialogue, a common language develops. This is language in the Saussurian sense, where terms and phrases used have no prescribed meaning, but rather, co-implication and shared meaning develop through negotiation (Cilliers, 1998). Language is more than just verbal exchange (Merleau-Ponty, 1962). It includes nonverbal and other interactions with the 'more than human world.' These are the sorts of interactions that are defined by culture, out of which situated and embodied action arise, institutionalized in an 'eduweb' where patterns are embedded and subsumed by the collective (Davis, 2007). Within a cultural group or other complex entity, "knowledge entails contextually appropriate action" (Davis, 2004, p. 147), action and learning that are situated within and among the individuals in the collective (Davis, Sumara \& Luce-Kapler, 2008).

On a superficial level, this is what could be expected through engagement with others in a classroom or other learning situation. But, on a deeper level, this is where individuals have the potential to learn from one other and develop into a learning collective. A possible result through collective and collaborative thinking within a cultural group is transcendence of individual potentiality whereby both the individual and collective are transformed into someone or something new. The emergent possibilities are then transformative and unlimited. This is a significant and explicit goal for culturally-responsive pedagogy.

\section{Discussion}

In this section of the paper, we begin a discussion for how complexivist thinking can inform culturally-responsive mathematics pedagogy. The goal is to expand thinking about how to develop and implement culturally-responsive pedagogical approaches. As suggested, a pedagogical approach that begins with Indigenous knowledge and the learners' cultural background through a critique of traditional hegemonic discourses inherent in current classroom practice, offers new and exciting possibilities for connecting students to the project of education. This is an important goal, as Aboriginal students in particular, but no means uniquely, face challenges and barriers within the public school system, and more particularly, in mathematics. An analysis of the factors that has led up to this situation is beyond the scope of this paper, although the range of 
issues makes it clear that no singular, unified strategy could begin to accomplish this large goal. Viewing the pedagogical project as a complex entity has its own challenges because complexity is enacted on so many levels.

Cultures of students, the community, school districts, teachers, subject areas and curriculum all represent complex systems with their own particularities. Interactions between and among these cultures (and others) specify and denote the learning system for the student and suggest opportunity for new possibilities for transformative education. Viewing a learning system as a complex system affords us a set of interpretive tools to understand the functioning of the system, and perhaps speculate on what might be yet needed to help all learners succeed and thrive within it.

We can begin to build a complex system that has the goal of developing culturallyresponsive mathematics pedagogies: we can bring a diversity of individuals into the conversation, and enable their interaction; we can encourage reflection and open spaces for dialogue; we can watch the process unfold and evolve, all the while being mindful that, as a complex system evolves, the learning system will also evolve in unexpected and surprising ways.

Learning itself is a complex, dynamic and emergent phenomenon. A wider view of complexity assumes that interaction, diversity and redundancy have a role in cognitive processing (Maturana \& Varela, 1980) and consciousness (Capra, 2002). According to Davis et al (2008), the system is the learner. This opens the field for discussion of how interactions, on many levels, contribute to the cognitive development of students. It also offers reasons for why diverse systems are able to respond to change, a necessary capability for any system functioning in a post-modern world (Cilliers, 1998). A mistake often made in institutional settings is a propagation (either consciously or not) of totalizing discourses. Culturally-responsive pedagogy acknowledges the heretofore totalizing discourses of mathematics and western science, and through examination of individuals functioning within the various systems and cultures, offers a different conceptual framework for teaching and learning.

As a background to the complex job of teaching, developing approaches to help learners be more successful is of imminent concern for teachers and teacher educators. Characteristics of complex systems are useful for elaborating the role of pedagogy to help learners succeed. In moving from a traditional role of teacher as knowledge-giver (and student as knowledge-receiver), to a complex learning system where interactions among agents within the system hold transformative potential, the teacher's role becomes one of facilitating, enabling and participating. A deep awareness and understanding of the students' cultural backgrounds, life experiences and connections to the community are prerequisite for the development of appropriate pedagogical approaches that have the potential to connect learners to each other, their communities and the educative process. In this view of teachers' work, teaching is participating in the cultural production of personal and collective knowledge. Teachers' deep understanding of mathematics concepts is important too, as this content knowledge builds and bridges cultural connections. 
Individual knowledge, collective knowledge and cultural identity interweave activity in classrooms. The biological metaphors of fitness and adaptation to this social, cultural and educational realm are appropriate. Fitness suggests adequacy for the situation at hand, meeting the emergent needs rather than maximizing or specifying responses. Adaptability is a quintessential characteristic within a web of relations. The interconnections among the agents of the system offer a resilience and sufficiency out of which the complex entity emerges. This is how learning about new things and one's self are intertwined with the pedagogical project of schooling.

Because mathematics pedagogy is one focus of culturally-responsive approaches, viewing mathematics education through a complexivist lens is also fruitful. As a domain of knowledge, mathematics has been accorded high status. And along with physics, it is seen by some (including mathematics and physics teachers) to be a proving ground for only the most capable of students (Nashon \& Nielsen, 2007). This is part of the totalizing discourse discussed earlier that has served to exclude Aboriginal students from advancement in the subject area and related career opportunities. It is important to avoid advocating a particular method or strategy as a panacea for the problem that is mathematics education for Aboriginal children. Instead, using the students' culture as an entry point for learners to gain a deeper understanding of themselves within their communities, as well as bridging the gap between Western mathematics and cultural traditions, offers the potential we would like to imagine for the enterprise of public schooling. Through a complexivist lens, we can examine the interrelatedness of these important issues in mathematics education.

\section{Implications for Mathematics Pedagogy}

To conceptualize culturally-responsive mathematics pedagogy as a learning system (and thus, a complex entity) enables us to consider how cultural norms, values, beliefs and practices are interrelated and implicated in how students approach learning and how teachers approach the job of organizing for instruction. It also offers insight into reconceptualization of the subject area of mathematics to acknowledge these important interrelations. Further, there are implications for how we ought to organize classrooms, engage teachers in professional development, and inform organization of pre-service teacher education programs. Classrooms are abundantly variable, and so need to be organized to facilitate relationality among students, teachers, cultural activities and language. Complexity theory sees variation as both a source and an outcome of thinking, rather than as a series of factors to be controlled in a predetermined, mechanistic way. Using a series of pedagogical tools that are based in the knowledge, traditions and practices of the local Aboriginal culture has the potential to deepen students' connections to the learning process, which in turn can connect learners to the wider society. The role for the teacher is facilitative and organizational, not prescriptive. For the expansive possibility of a complex unity to emerge, the various aspects of complexity need to be enabled. This begins early in the project of organizing for curriculum and instruction. Building specific relationships with those who hold knowledge of the 
traditions and cultural practices of the community is a first step in bringing this knowledge into the classroom. This is knowledge that Aboriginal communities want in their schools, both as content and pedagogical practice. Teachers also need to be open to the examination of their own beliefs, values and experiences. In the interest of building better connections with and among their students, both to their own communities and to the subject areas in school, teachers must become learners (about the culture, its practices and traditions) and participants. This is the webbing of interactions that is so fruitful for generating new possibility.

This opens a potentially imaginative space for attempting to better understand the intricacies of learning systems, and a key space for teacher professional development. Through approaching the project as learners themselves, both in-service teachers and teacher candidates may thus be enabled to develop a new appreciation for the work of teaching. Becoming part of a complex entity that is designed to be culturally-responsive is but one step along the way of ensuring that all students can be successful and benefit from the experience of schooling.

\section{Conclusion}

Theorizing learning systems within complexity theory allows us to widen our view to post-structural, post-epistemological frameworks that are culturally-responsive, decolonizing and empowering. Developing new research paradigms for studying schools, classrooms, learners and teachers creates new opportunity to develop deeper understandings of what goes on in learning situations as well as greater appreciation for the richness of pedagogical approaches based in non-western knowledge systems. Possibilities also emerge for building-in responsiveness to the cultural backgrounds of both the knowledge represented and students in the classroom. Culturally-responsive mathematics teaching and learning, so conceptualized, is an approach that offers the possibility of a deeper understanding of the historical, spiritual, emotional, cognitive, physical, and social aspects of Aboriginal worldviews and the lives of Aboriginal students. This responsiveness intends to meaningfully engage Aboriginal learners in the experience of schooling, thus offering wider potential for participation in post-secondary education, the community and society, and for individuals to emerge from school with the self-confidence and personal resources to actively participate at any of these levels.

The school project, despite its ups and downs, became a source of tremendous community pride. Some of the workers have gone on to other community infrastructure projects. However, the majority of those initially hired were in many ways unprepared for the demands of the work. This lack of preparation can be realistically placed at the level of the school system, which has been largely unable to successfully integrate community values and practices into the taught curriculum or teaching practices. The result has been a disconnect between the purposes of schooling and participation in adult, community life. Theoretically, the project of schooling through culturally-responsive pedagogy and complexivist thinking offers a framework for schooling to be expansive. Once approaches are adopted, more direct evaluation of their efficacy can be considered. This work remains in the future. 


\section{Acknowledgements}

A special thank you to Valerie Triggs, Moshe Renert, Gillian Gerhard, Rachel Moll, Juan Carlos Castro and Brent Davis for critical feedback on early drafts of this paper. We would also like to thank the three anonymous reviewers for their helpful feedback and enthusiastic support for this paper, as well as our colleagues on the TEAM-UBC project.. This research was supported in part by grants from the Social Sciences and Humanities Research Council of Canada (Grant No. 410-2005-0755), the Vancouver Foundation, and the Canadian Council on Learning. The project website can be accessed at http://www.cust.educ.ubc.ca/team/project_sites.html.

\section{References}

Aikenhead, G. S. (1996). Science education: Border crossing into the subculture of science. Studies in Science Education 27, 1-52.

Aylward, M. L. (2007). Discourses in cultural relevance in nunavut schooling. Journal of Research in Rural Education 22(7): Retrieved June 27, 2007 from http://www.umaine.edu/jrre/22-7.pdf

Barnhardt, R. and Kawagley, A. O. (1998). Culture, chaos and complexity: Catalysts for change in indigenous education. (ERIC Document Reproduction Service No. ED425032)

Barnhardt, R. and Kawagley, A. O. (2005). Indigenous knowledge systems and alaska native ways of knowing. Anthropology and Education Quarterly 36(1), 8-23.

Battiste, M. (2002). Indigenous knowledge and pedagogy in First Nations education: A literature review with recommendations. Prepared for the National Working Group on Education and the Minister of Indian Affairs, Indian and Northern Affairs, Ottawa Ontario, Canada.

Battiste, M. (2004). Animating sites of postcolonial education: Indigenous knowledge and the humanities. Paper presented at the Annual meetings of the Canadian Society for Studies in Education, Winnipeg, MB, May, 2004.

Battiste, M. (2005). Indigenous knowledge: Foundations for First Nations. World Indigenous Higher Education Consortium [WINHEC] Journal. Last retrieved March 22, 2007 from http://www.winhec.org/?q=node $/ 34$

Battiste, M. and Barman, J. (1995). First Nations education in Canada: The circle unfolds. Vancouver, BC: University of British Columbia.

Bishop, A. J. (1988). Mathematics enculturation: A cultural perspective on mathematics education. Dordrecht: Kluwer Academic.

Bishop, A. J. (1994). Cultural conflicts in mathematics education: Developing a research agenda. For the Learning of Mathematics 14(2), 15-18.

British Columbia Ministry of Education. (2000). Mathematics 10-12: Integrated resource package. Province of British Columbia: Ministry of Education.

British Columbia Ministry of Education. (2004). How are we doing? Demographics and performance of Aboriginal students in BC public schools. British Columbia Ministry of Education Foundation Skills Assessment Results. Available: http://www.bced.gov.bc.ca/abed/performance.htm

British Columbia Ministry of Education. (2006a). Aboriginal report-2005/06: How are we doing? British Columbia Ministry of Education Knowledge Management Department. Available: http://www.bced.gov.bc.ca/abed/performance.htm

British Columbia Ministry of Education. (2006b). Graduation program: optional examinations: course $\mathcal{E}$ exam results Grade 12 (2006/07). British Columbia Ministry of Education Knowledge Management Department. Retrieved December 28, 2007 from http://www.bced.gov.bc.ca/reporting/exams/opt/

British Columbia Ministry of Education. (2006c). Graduation program required examinations: Course and exam results 2004/05-2005/06 full year summary report. British Columbia Ministry of Education Knowledge Management Department. Retrieved December 28, 2007 from http://www.bced.gov.bc.ca/reporting/levels/prov-bas.php 
British Columbia Ministry of Education. (2007). Graduation program requirements. Retrieved December 30, 2007 from http://www.bced.gov.bc.ca/graduation/grad2004.htm

Burris, E. (2005). Classrooms can use therapy too. Complicity: An International Journal of Complexity and Education 2(1), 5-17.

Cajete, G. (1994). Look to the mountain: An ecology of indigenous education. Skyland, NC: Kivaki.

Capra, F. (1996). The web of life: A new scientific understanding of living systems. New York: Anchor.

Capra, F. (2002). The hidden connections: A science for sustainable living. New York: Anchor.

Cilliers, P. (1998). Complexity and postmodernism: Understanding complex systems. London: Routledge.

Coalition for the Advancement of Aboriginal Studies. (2002). Learning about walking in beauty: Placing Aboriginal perspectives in Canadian classrooms. Toronto, ON: Canadian Race Relations Foundation. Available: http://www.crr.ca/

Cooper, T., Batura, A., Warren, E. and Doig, S. (2006). 'Aim high-Beat yourself': Effective mathematics teaching in a remote indigenous community. In J. Novotná, H. Moraová, M. Krátká and N. Stehliková (Eds.). Proceedings of the 2006 International Group for the Psychology of Mathematics Education: Vol. 2. Prague, Czech Republic: Charles University.

D'Ambrosio, U. (1990). The role of mathematics education in building a democratic and just society. For the Learning of Mathematics 10(3), 20-23.

Davis, B. (2004). Inventions of teaching: A geneology. Mahwah, NJ: Erlbaum.

Davis, B. (2007). Learners with/in contexts that learn. In T. Lamberg and L.R. Wiest (Eds.). Proceedings of the 29th Annual Meeting of the North American Chapter of the International Group for the Psychology of Mathematics Education (pp. 19-32). Stateline, NV: University of Nevada, Reno.

Davis, B., R. Phelps, and Wells, K. (2004). Complicity: An introduction and a welcome. Complicity: An International Journal of Complexity and Education 1(1), 1-7.

Davis, B., and Simmt, E. (2003). Understanding learning systems: Mathematics education and complexity science. Journal for Research in Mathematics Teaching, 34, 137-167.

Davis, B. and Sumara, D. (2001). Learning communities: Understanding the workplace as a complex system. New Directions for Adult and Continuing Education 92, 85-95.

Davis, B. and Sumara, D. (2006). Complexity and education: Inquiries into learning, teaching and research. Mahwah, NJ: Lawrence Erlbaum.

Davis, B., Sumara, D. and Luce-Kapler, R. (2008). Engaging minds: Changing teaching in complex times (2nd ed.). New York: Routledge.

Ezeife, A. N. (2002). Mathematics and culture nexus: The interactions of culture and mathematics in an Aboriginal classroom. International Education Journal 3(2), 176-187.

Friere, P. (1994). Pedagogy of hope: Reliving pedagogy of the oppressed. New York: Continuum.

Gutstein, E. (2006). Reading and writing the world with mathematics: Toward a pedagogy of social justice. New York: Routledge.

Hampton, E. (1995). Towards a redefinition of indian education. In M. Battiste and J. Barman (Eds.). First Nations education in Canada: The circle unfolds (pp. 4-6). Vancouver, BC: University of British Columbia.

Industry Training Authority. (2007). Industry training program profile accredited training program carpenter. Retrieved December 28, 2007 from http://www.itabc/TrainingPrograms Profiles.php?TradeProfileID=4

Ladson-Billings, G. (1995). Toward a theory of culturally relevant pedagogy. American Educational Research Journal 32(3), 465-491.

Leavitt, R. (1995). Language and cultural content in Native education. In M. Battiste and J. Barman (Eds.). First Nations education in Canada: The circle unfolds (pp. 124-136). Vancouver, BC: University of British Columbia.

Lipka, J. (2002). Schooling for self-determination: Research on the effects of including Native languages and culture in schools. ERIC Digest ED459989. Charleston, WV: ERIC Clearing House. 
Lipka, J., Webster, J., Yanez, E. and Andrew-Ihrke, D. (2006). Math in a cultural context: Yup'ik Eskimo pedagogical perspectives. Paper presented at the annual meetings of the American Educational Research Association, San Francisco, CA, April, 2006.

Maturana, H.R. and Varela, F. J. (1980). Autopoeisis and cognition. Dordrecht, Holland: D. Reidel.

Maturana, H.R. and Varela, F. J. (1987). The tree of knowledge: The biological roots of human understanding. Boston: Shambhala.

Merleau-Ponty, M. (1962). Phenomenology of perception. London: Routledge.

Nashon, S. M. and Nielsen, W. S. (2007). Factors impacting students' decisions around Physics 12. Canadian Journal of Research in Science, Mathematics and technology education 7(2/3), 93-106.

Nielsen, W. S. and Nashon, S. M. (2007). accessing science courses in rural BC: A Cultural border crossing metaphor. Alberta Journal of Educational Research 53(2), 174-188.

Royal Commission on Aboriginal Peoples. (1996). People to people, nation to nation: Highlights from the Royal Commission on Aboriginal peoples. Ottawa, ON: Minister of Supply and Services.

Simon, H. (2005). The architecture of complexity. E:CO 7(3), 138-154. (Reprinted from Proceedings of The American Philosophical Society 106(6), 467-482, 1962).

Waldrop, M. M. (1992). Complexity: The emerging science at the edge of order and chaos. New York: Simon \& Schuster.

Yamauchi, A. I., Ceppi, A. K. and Lau-Smith, J. (2000). Teaching in a Hawaiian context: Educators perspectives on the Hawaiian language immersion program. Bilingual Research Journal 24(4), 385403.

\begin{abstract}
About the Authors
Dr. Wendy S. Nielsen and Dr. Jenipher Owuor are recent graduates of the Department of Curriculum Studies at the University of British Columbia. Wendy is a science and mathematics educator. Jenipher is interested in business education. Both have research interests in teacher education and multicultural education. Dr. Cynthia Nicol is an Associate Professor of Mathematics Education in the Department of Curriculum Studies, also at the University of British Columbia. Her research interests include mathematics teacher education, culturally responsive pedagogy, Indigenous education, and action research. Email correspondence should be addressed to Wendy S. Nielsen at nielsenw@gmail.com, Cynthia Nicol atcynthia.nicol@ubc.ca, and Jenipher Owuor at jaowuor@yahoo.com.
\end{abstract}

(C) Copyright 2008. The authors, WENDY S. NIELSEN, CYNTHIA NICOL and JENIPHER OWUOR assign to the University of Alberta and other educational and non-profit institutions a non-exclusive license to use this document for personal use and in courses of instruction provided that the article is used in full and this copyright statement is reproduced. The author also grants a nonexclusive license to the University of Alberta to publish this document in full on the World Wide Web, and for the document to be published on mirrors on the World Wide Web. Any other usage is prohibited without the express permission of the authors. 